\title{
A Filosofia e seu ensino a partir de uma perspectiva da teoria crítica
}

\section{Philosophy and its teaching from a critical theory perspective}

\author{
Gelson João Tesser ${ }^{1}$ \\ Geraldo Balduíno Horn ${ }^{2}$ \\ Delcio Junkes ${ }^{3}$
}

\begin{abstract}
RESUMO
Este artigo analisa dois pressupostos teóricos considerados centrais da prática do ensinar e aprender Filosofia: o agir comunicativo em Habermas e o pensar como forma de resistência em Adorno. A Filosofia e seu ensino em Habermas são desenvolvidos a partir da teoria do agir comunicativo, proporcionando-nos uma base teórica de reflexão, de uma educação racional e crítica. Na perspectiva adorniana, a função social do ensino está intrinsecamente ligada à crítica da sociedade burguesa e, por conseguinte, com a indústria cultural. Adorno procura mostrar que a educação formal tem um forte poder de resistência em relação ao rumo caótico do processo civilizatório. Aproximar esse sentido adorniano de resistência à prática de ensinar Filosofia é o intento proposto aqui. Ensinar Filosofia significa não aceitar as imposições políticas, institucionais e sociais como sendo naturais. A tarefa da Teoria Crítica - da Filosofia como ensino -, tem uma dimensão que remete à busca do exercício da autonomia do sujeito e de sua emancipação social.
\end{abstract}

Palavras-chave: agir comunicativo; resistência; emancipação; ensino de Filosofia.

${ }^{1}$ Doutor em Educação pela Universidade Estadual de Campinas (UNICAMP). Professor de Filosofia da Educação do Departamento de Teoria e Fundamentos da Educação da Universidade Federal do Paraná - (DTFE/UFPR). E-mail: gelson@ufpr.br

${ }^{2}$ Doutor em Filosofia da Educação pela Faculdade de Educação de São Paulo (FEUSP). Professor de Metodologia e Prática de Ensino de Filosofia do Departamento de Teoria e Prática de Ensino da UFPR (DETPEN/UFPR).

${ }^{3}$ Doutor em Filosofia pela Universidade Federal de São Carlos (UFSCAR). Professor de Filosofia da Educação do DTFE/UFPR. 


\begin{abstract}
This paper analyzes two central theoretical assumptions regarded in the practice of teaching and learning philosophy: communicative action in Habermas and thinking as a way of resistance in Adorno. Philosophy and its teaching are developed from Habermas's theory of communicative action which provides us with a theoretical basis for reflection and critical education. In the Adornian perspective, the social function of education is intrinsically linked to the critique of the bourgeois society and, therefore, the cultural industry. Adorno seeks to show that formal education has a strong power of resistance against the chaotic path of civilization. Bringing this Adornian sense of resistance to the practice of Philosophy teaching is the purpose proposed here. Teaching Philosophy does not consist of accepting the political, institutional and social enforcements as natural. The task of Critical Theory - as teaching Philosophy -, has a dimension that refers to the pursuit of autonomy by the individual and his social emancipation.
\end{abstract}

Keywords: communicative action; resistance; emancipation; Philosophy teaching.

\title{
Introdução
}

Explicitamente não temos uma obra que fala sobre educação na perspectiva de Habermas abordada por ele mesmo, embora seus escritos e ensaios oportunizem refletir sobre a dimensão pedagógica a partir da teoria crítica e do agir comunicativo, em que a racionalização é um processo pelo qual acontece a ampliação do conhecimento, não só na esfera instrumental, mas também na dimensão comunicacional, como um suporte para dimensionar a educação como socialização. O processo de ensino só poderá ser considerado emancipatório se acontecer na instância do agir comunicativo e não na do puramente instrumental. A perspectiva filosófica habermasiana insere o saber na esfera do esclarecimento, no contexto da razão comunicativa e da reflexão crítica, no âmbito da teoria e da prática. O interesse válido e verdadeiro do conhecimento educacional deverá ser o da emancipação.

O pensamento habermasiano, originado na reflexão sobre a razão encarnada na cognição, fala e ação, é indispensável como teoria crítica atualmente, quando predomina a ideia central de uma racionalidade econômica e burocrática do sistema que penetra crescentemente nas esferas do mundo e da vida, colonizando-a e levando, dessa maneira, a perdas de liberdade e de sentido. 
Hoje vivemos em democracias de massa sob condições da propaganda política calculada, ao invés de discursos racionais críticos entre iguais. "A decadência se iniciou sob as condições da sujeição à lógica do poder econômico e da substituição política da publicidade por estratégias de propaganda sociopsicologicamente calculadas" (REESE-SCHÄFER, 2009, p. 32-33). Como racionalidade comunicativa, a educação é necessária ao ser humano justamente para impedir a degradação humana.

Já a perspectiva adorniana de educação e ensino parte da compreensão de que o locus da educação escolar e, por conseguinte, do ensino de Filosofia, tem a ver com formação e cultura geral (Bildung) e com a possibilidade de oferecer um espaço de crítica sistemática em relação à escolarização, fundamentada, de um lado, na tecnificação e na especialização exacerbada, comprometida com as demandas produzidas pela lógica do mercado, e, de outro, na manutenção do sistema social e político vigente sem que se produza uma alternativa de resistência. Na medida em que a educação escolar perde sua referência como espaço da produção do saber sistemático e crítico, dá lugar à semicultura e legitima a formação fragmentada, pragmática, referendada pelo modelo social vigente - o capitalismo.

\section{O agir comunicativo e o ensino de Filosofia}

O conceito de agir comunicativo leva em conta o entendimento linguístico como mecanismo de coordenação da ação e faz com que as suposições contrafactuais dos atores que orientam seu agir por pretensões de validade adquiram relevância imediata para a construção e a manutenção de ordens sociais, pois estas se mantêm no modo do reconhecimento de pretensões de validade normativas, que visam à socialização dos sujeitos. A linguagem é tida como meio de integração social. No uso da linguagem orientada pelo entendimento, os participantes unem-se em torno da pretensa validade criticável de suas ações de fala, que apontam para o reconhecimento recíproco intersubjetivo. No agir comunicativo, os participantes da interação têm de se atribuir reciprocamente a consciência de seus atos e orientá-los por pretensões de validade, eticamente discursivos.

O agir comunicativo leva em consideração o mundo da vida que nos envolve (linguagem, cultura, trabalho, interação, educação). É nesse mundo que se forma o horizonte para situações de fala e é ele que se constitui, ao mesmo tempo, na fonte das interpretações, reproduzindo-se através de ações comunica- 
tivas. É no mundo da vida que acontece o processo subjetivo de aprendizagem. A educação como processo de formação de ampliação da socialização e aprofundamento das relações sociais, bem como a expansão da reflexão e criação de uma cultura potencialmente emancipatória libertadora, estão implícitas na obra de Habermas. A liberdade comunicativa está referida, antes de qualquer institucionalização.

O processo de ensino no âmbito universitário no mundo inteiro caracteriza-se por funções nucleares da pesquisa e pela promoção de jovens pesquisadores, pela preparação acadêmica ligada às profissões e pela produção de um saber aplicável ao desenvolvimento, por tarefas de formação geral e por contribuições ao autoentendimento cultural e ao esclarecimento intelectual. Habermas desenvolve o conceito de agir comunicativo como um processo de caráter linguístico de validade universal. O sujeito, nessa perspectiva, toma consciência da sua dimensão de participante numa comunidade de falantes. A racionalidade se manifesta como um suporte acoplado à dimensão da comunicação.

A linguagem apresenta um caráter normativo universal e a razão, então, é o fundamento do processo discursivo. "O que torna a razão comunicativa possível é o medium linguístico, através do qual as interações se interligam e as formas de vida se estruturam" (HABERMAS, 1997, p. 20). Todo aquele que age comunicativamente leva em consideração a inteligibilidade, a verdade, a correção (em referência a normas) e a veracidade. A aprendizagem pode acontecer tanto na esfera ética e moral da vida como na esfera cognitiva, fundamentada em procedimentos discursivos de argumentação.

A linguagem passa a ser considerada na ação comunicativa como um medium universal de incorporação da razão. O pensamento está interligado com a linguagem. Pensar é fazer apreciações críticas. As ideias passam a ser concebidas como incorporadas na linguagem, de tal modo que as expressões linguísticas que surgem no mundo ligam-se internamente com a idealidade da universalidade do significado e da validade em termos de verdade. O medium da linguagem se estende para além dos limites da racionalidade comunicativa.

A racionalidade comunicativa exprime-se numa práxis de fala, que, com seus papéis dialogais e pressupostos comunicativos, é talhada para uma meta de reconhecimento intersubjetivo com pretensões de validade. Em educação não é permitido blefar, mentir, iludir, enganar, ludibriar, distorcer, mascarar. É permitido, sim, falar, dizer a verdade, ou seja, ter sempre em mente as pretensões de veracidade. "O acompanhamento reflexivo da práxis da justificação no mundo vivido, do qual nós mesmos participamos como leigos, permite traduções reconstrutoras que incentivam uma compreensão crítica. O filósofo amplia a perspectiva de participação fixada para além do círculo dos participantes imediatos" (HABERMAS, 2002, p. 14). 
A teoria do agir comunicativo possibilita aos sujeitos o desencadeamento de entendimentos decorrentes do processo de diálogo. O agir pedagógico é um agir que visa a uma ação de caráter instrumental, estratégico, técnico, empírico, que não pode ser absolutizado nesse paradigma. Portanto, a Pedagogia intenciona teleologicamente alcançar fins de caráter comunicacional que estão para além do instrumental. $\mathrm{O}$ ato educativo constitui um agir normativo regido por valores que explicitam a necessidade de participação e envolvimento do sujeito no processo de constituição de si mesmo e do outro. No agir comunicativo, o indivíduo vivencia experiências que oportunizam consensos e entendimentos no processo de busca da verdade.

$\mathrm{O}$ agir comunicativo de Habermas apresenta um caráter reflexivo para a educação na medida em que sinaliza para a superação da ação instrumental coisificante do ser humano. O processo educacional consiste na renovação permanente do saber e das experiências no processo de formação da personalidade. Há um interesse explícito na Filosofia de Habermas pela emancipação, socialização e intersubjetividade: "Meu interesse fundamental está voltado primordialmente para a reconstrução das condições realmente existentes, na verdade sob a premissa de que os indivíduos socializados, quando no seu dia a dia, se comunicam entre si através da linguagem" (HABERMAS, 1993, p. 98).

A educação poderá ser vista como um desenvolvimento (formação) da racionalidade epistêmica, teleológica, comunicativa. Pode-se dizer que, para Habermas, a educação é uma práxis reflexiva abarcada pelo agir comunicativo, em que a aprendizagem fundamentacional é corporificada no discurso e encarnada nas ações cotidianas de transformação de si e do mundo. Tal modo de entender a educação pressupõe uma ordem institucional e condições sociais que favoreçam o desenvolvimento da pessoa. A práxis comunicativa é condição para mediação da cultura e desenvolvimento pessoal numa relação intersubjetiva e partilhada pedagógica e filosoficamente. A aprendizagem deveria ser compreendida em um contexto abrangente, abrindo processos de formação social, cultural, científica, em todas as esferas onde eles acontecem no mundo da vida.

A teoria do agir comunicativo é construída a partir do horizonte da compreensão do mundo e da realidade por parte dos educandos. Na comunicação solidária e intersubjetiva, o sujeito aparece em sua dignidade própria como alguém que não pode ser reduzido a sua dimensão instrumental. A relação professor-aluno depende do reconhecimento recíproco entre sujeitos e se encaminha numa dimensão libertadora. No processo educativo, o reconhecimento do outro, a não coação da comunicação e a disposição para a solução de problemas através do diálogo "discurso" livre e igual é um fator preponderante que serve de base para a convivência humana. 
Os lugares privilegiados da aprendizagem (cognição) são a sala de aula (escola, universidade) e o mundo da vida. No diálogo, na intersubjetividade de um mundo da vida partilhado, reciprocamente referente e mediado pela linguagem, pelo agir comunicativo, está assegurada aos atores do processo educacional a liberdade de pensamento. Segundo Habermas, "o emprego comunicativo da linguagem entrelaça-se com sua função cognitiva" (HABERMAS, 2004, p. 70).

Implicitamente, Habermas contribui para o ensino de Filosofia e uma Pedagogia comunicativa, livre de bloqueios, repressões e distorções ideológicas. A educação do sujeito acontece pela via da ação comunicativa, na medida em que os sujeitos têm consciência e competência como falantes e participantes de uma comunidade de fala. No agir comunicativo, os seres humanos ampliam a sua consciência crítica e suas competências racionais intersubjetivas, como atores diretos da interação social. A ação pedagógica, no contexto comunicativo da intersubjetividade, engaja os aprendizes como participantes em potencial.

A criança que já consegue falar já aprendeu a endereçar um proferimento a um ouvinte numa intenção comunicativa e, inversamente, a se compreender como destinatária de semelhante proferimento. Ela passa a dominar uma relação eu-tu recíproca entre falantes e ouvintes logo que consegue distinguir entre dizer e fazer (HABERMAS, 1989a, p. 178).

Nos processos de comunicação se constituem a identidade do indivíduo e as dimensões da sociabilidade dos sujeitos. Para Habermas, "o agir comunicativo permite o entrelaçamento de individuação e socialização" (HABERMAS, 2004, p. 96). A educação é um processo comunicativo que consiste na libertação dos envolvidos no processo de fala. A liberdade comunicativa dos cidadãos pode assumir, na prática da autodeterminação organizada, uma forma mediada através de instituições e processos jurídicos. A situação ideal de fala exclui as distorções da comunicação.

A ciência e a técnica invadiram o mundo da vida e o controlam, impondo suas lógicas instrumentais de dominação. A ciência e a técnica são elementos estruturantes da vida social, cultural e individual na sociedade econômica capitalista do lucro. Segundo Habermas, "la acción instrumental se orienta por reglas técnicas, que descansan en un saber empírico. De otro lado, por acción comunicativa, entiendo una interación simbólicamente mediada" (HABERMAS, 1989b, p. 27). 
Habermas propõe uma ética discursiva de caráter emancipatório. A ética refere-se ao bem do indivíduo ou da comunidade, ao passo que a moral tem a ver com a justiça. Segundo Habermas, "as argumentações morais são institucionalizadas através de meios jurídicos” (HABERMAS, 1986, p. 15). Do ponto de vista da ética do discurso, os sujeitos capazes de falar e agir julgam as ações e conflitos relevantes com relação ao universo, a ser realizado, de relações interpessoais bem ordenadas, no qual os atores do processo projetam para si "as orientações de conduta, que transcendem a tacanhez dos interesses puramente privados; os interesses de cada um orientados para a autorrealização devem estar aqui em sintonia com os interesses de todos" (HABERMAS, 1999, p. 42).

$\mathrm{Na}$ perspectiva de Habermas, a Filosofia é um elemento indispensável para o desenvolvimento de uma razão crítica emancipadora. Ela pode contribuir especificamente para a autocompreensão das sociedades modernas, calcada no diagnóstico da época. Ela pode também ser uma autocrítica da razão. Contribuir com a visão do todo. Em seu texto Compreender Habermas, Walter Reese-Schäfer destaca um papel para a Filosofia em que ela própria abriu para si uma nova dimensão, "de uma crítica material da ciência. É que ela se posicionaria contra a dupla irracionalidade de uma autocompreensão positivista limitada das ciências e contra uma administração tecnocrática deslocada da formação discursiva da vontade" (REESE-SCHÄFER, 2009, p. 141). De modo muito peculiar, ela pode criticar a colonização do mundo da vida pela ciência, pela técnica, pelo mercado, pelo capital, pelo direito e pela burocracia. Ela pode, sim, pleitear uma vida normativa e ética. "O efeito público do pensamento filosófico necessita, numa medida especial, da proteção institucional da liberdade de pensamento e de comunicação; inversamente, um discurso democrático, sempre ameaçado, também depende da vigilância e da intervenção desse guardião publico da racionalidade" (HABERMAS, 2004, p. 324).

A Filosofia como ensino não poderá desalojar ou substituir a religião, nem a ciência, nem a arte, mas sem ela não será possível desenvolver uma crítica e uma reflexão radical, rigorosa, de conjunto dos saberes. "A tarefa filosófica propriamente dita consiste, então, em estabelecer uma conexão plausível entre aquilo que é funcional para o observador e aquilo que é considerado racional para os participantes" (HABERMAS, 2002, p. 29). Nesse sentido, os seres humanos continuam tendo necessidade de fazer uso crítico-reflexivo da razão como síntese formadora do mundo e integrada à linguagem e aos contextos de ação, para possibilitar a educação como transformação de si e da realidade. 


\section{O pensar filosófico como forma de resistência}

"Quem pensa impõe resistência". Esse pensamento adorniano é tomado aqui como referência para se compreender o ensino de Filosofia como forma de expressão do pensar sistemático e reflexivo e, portanto, como forma de resistir aos lugares-comuns e conclusões apressadas que, geralmente, nos induzem a práticas sociais e educacionais pouco consistentes. Para desenvolver esse entendimento, utilizaremos, mesmo que de modo sucinto, alguns conceitos de Adorno, como dialética negativa, razão instrumental, indústria cultural e razão emancipatória (alguns deles construídos em parceria com Horkheimer).

Em Dialética negativa, Adorno mostra que o trabalho filosófico deve abandonar a ilusão de que, por força do pensamento, é possível captar a totalidade do real. Adorno baseia-se na dialética que nega a identidade entre realidade e pensamento. A pretensão de captar a totalidade do real, revelando-lhe o sentido do oculto e profundo, é ilusória, crença típica das metafísicas tradicionais, da fenomenologia, do idealismo, do positivismo, do marxismo oficial e do iluminismo, que acreditavam que o ser é de fato correspondente ao pensamento e a ele acessivel. Essas teorias positivas podem facilmente se transformar, como, de fato, se transformam, em ideologias.

A realização do pensar filosófico cuidadoso, em Adorno, se dá por meio de uma dialética da negação e não simplesmente pela síntese e conciliação de componentes opostos. Após Auschwitz, é preciso afirmar a não identidade entre ser e pensamento, para não camuflar a realidade, para que a razão não adquira um caráter totalitário.

Nas palavras do próprio Adorno:

Cuando el pensamiento se abisma en lo que tiene inicialmente frente a si, el concepto, y se da cuenta de su inmanente antinomia, está acariciando ya la idea de algo más allá de la contradicción. La contraposición del pensamiento con lo que le es heterogéneo se produce como contradicción inmanente del pensamiento mismo. La crítica que se hacen recíprocamente lo universal y lo particular consiste en actos identificantes, que juzgan sobre si el concepto corresponde a su contenido o lo particular y el concepto. [...] El contenido del pensamiento filosófico consiste ni en los restos que quedan trás tachar tiempo y espacio ni en constataciones generales sobre lo espaciotemporal. La Filosofía cristaliza en lo especial, determinado espacial y temporalmente. El concepto de ente puro no es sino la sombra del falso concepto de ser. (ADORNO, 1975, p. 141-142). 
Sob essa perspectiva de análise, pode-se compreender a dialética negativa como caminho de investigação e como atitude de vida, na medida em que se situa contra o domínio do idêntico, de modo que os particulares se rebelam contra o universal abstrato, metafísico ou de caráter ideológico. Ela não pode ser entendida, simplesmente, como uma técnica de produção de sínteses formais. $\mathrm{Na}$ verdade, seu sentido só se concretiza quando cumpre uma função de crítica da cultura ou mesmo de teoria crítica da sociedade. Nesses termos, a dialética negativa como leitura e análise dos fenômenos reais não é nem idealista, que traduz os fenômenos reais em simples esquemas conceituais e argumentos lógica e formalmente bem construídos pelo sujeito cognoscente, nem empirista, que reconhece apenas o conhecimento que é produzido a partir da comprovação por meio da experiência ou prova laboratorial. Ao contrário, trata-se, sim, de uma dialética materialista, que necessariamente reconhece a contradição como elemento de tensão entre sujeito e objeto capaz de produzir conhecimentos que reconhecem tanto a singularidade como a universalidade, o particular como a totalidade, o abstrato como o concreto, ou seja, não há conhecimento em si: todo conhecimento é teórico e prático. Por isso, é também uma tomada de posição política.

Outro conceito-chave utilizado por Adorno, formulado em parceria com Horkheimer a partir da herança weberiana, é a razão instrumental. Esse conceito é fortemente ligado ao iluminismo/esclarecimento, que os autores entendem não só como o movimento de pensamento da época das luzes, mas como algo muito mais além, num itinerário da razão que inicia com os gregos. Estes já teriam visto na razão um instrumento que, ao mesmo tempo em que é capaz de explicar a natureza, liberando o homem do desconhecido, também é capaz de dominá-la, domínio esse que, por fim, se estende ao próprio ser humano: "A racionalidade técnica hoje é a racionalidade da própria dominação. Ela é o caráter compulsivo da sociedade alienada de si" (ADORNO; HORKHEIMER, 1985, p. 114).

Adorno e Horkheimer não consideram que a razão instrumental seja um aspecto essencialmente nocivo da razão, admitindo até que ela auxiliou na criação de condições para que a razão emancipadora pudesse se desenvolver. Porém, ela se torna perigosa quando invade esferas onde deveria prevalecer o princípio emancipador, como na produção cultural. Esse processo de perversão nos propósitos da produção da cultura gerou o surgimento do que eles denominaram de indústria cultural, que é constituída essencialmente pelos mass media (cinema, televisão, rádio, discos e publicidade, entre outros meios) e funciona como um instrumento de uma poderosa máquina colocada em movimento pela sociedade tecnológica contemporânea e que gradualmente foi transformando todos os produtos culturais em mercadoria. 
$\mathrm{O}$ cinema e o rádio não precisam mais se apresentar como arte. A verdade de que não passam de um negócio, eles os utilizam como uma ideologia destinada a legitimar o lixo que propositalmente produzem. Eles se definem a si mesmos como indústrias, e as cifras publicadas dos rendimentos de seus diretores gerais suprimem toda dúvida quanto à necessidade social de seus produtos. (ADORNO; HORKHEIMER, 1985, p. 114).

A indústria cultural programa e cria regras até para o tempo livre. As atividades antes desenvolvidas com autonomia pelos indivíduos durante o tempo de ócio ou de lazer são absorvidas pelo entretenimento, que se caracteriza basicamente por ser um acúmulo de atividades cujo objetivo é estender o ritmo do trabalho e da produção de forma administrada, certificando-se de que tenha sido eliminado qualquer potencial emancipador na forma como o tempo livre é ocupado. Daí por que ela se constitui como uma ideologia: ela própria é ideologia; ideologia da aceitação dos fins estabelecidos pelo mercado.

O iluminismo transformou-se no seu contrário. Tinha no seu programa a intenção de eliminar os mitos, mas acabou caindo na sua própria armadilha, criando-os desmedidamente. Kant apregoava a saída do homem de sua condição de menoridade com o uso da própria razão, sem direção de outrem. Nada disso aconteceu até aqui. O indivíduo de hoje é zero, é nada, é absolutamente guiado por outros. Dizia-se, em outros tempos, que o destino do indivíduo estava escrito nas estrelas; hoje, porém, pode-se dizer que a direção que o indivíduo assume é determinada pela sociedade tecnológica. Isso fica claro quando pensamos nas pesquisas empíricas, principalmente as de Sociologia, que se interessam pelo que as pessoas pensam mais pela ótica daquilo que o mercado pede do que pelo que as pessoas pensam de determinada maneira.

Do ponto de vista da análise frankfurtiana, é preciso fazer uma distinção entre indústria cultural e cultura de massa. A cultura de massa, segundo Adorno, não é adequada para traduzir a produção e o consumo de produtos culturais em larga escala. Confunde-se com a ideia de arte espontânea e cultura e arte popular mais do que com comercialização de produtos culturais. A indústria cultural é uma cultura imposta de cima para baixo, com o intuito de adaptar e integrar as massas à ordem social vigente. Ela se realiza, principalmente, pela padronização dos produtos e pela racionalização das técnicas de divulgação, formadas pelo amplo aparato dos meios de comunicação.

Mas o que isso tudo tem a ver com a Filosofia, ainda mais quando a pensamos, principalmente, como uma disciplina escolar? Teria a Filosofia uma contribuição específica na formação do sujeito em processo de escolarização que a diferencia da História, da Psicologia, da Sociologia ou de outro campo 
do conhecimento? Sim. A Filosofia é, ao mesmo tempo, interpretação e formação cultural, conhecimento e engajamento político; é intuição e racionalidade emancipatória, método e conteúdo; é, ao mesmo e a um só tempo, realização humana e subjetivação da existência; é prática social e substancialização do sentido mais propriamente singular da natureza humana. Enfim, a Filosofia é a negação de sua própria afirmação, pois ela só se torna possível quando sai de si, quando suspende as ideias sobre o mundo, para relê-lo como presente perpassado de contradições.

A Filosofia e a realização do pensar por meio de um ensino que supere a mera repetição e memorização têm a ver necessariamente com a compreensão e o sentido dado por Adorno àquilo que é denominado de razão emancipatória. A noção de razão emancipatória passa pela análise crítica do sentido de esclarecimento em Kant, bem como pela crítica à visão pragmática de razão do movimento iluminista e da transformação da razão em razão instrumental.

[...] emancipação significa o mesmo que conscientização, racionalidade. Mas a realidade sempre é simultaneamente uma comprovação da realidade, e esta envolve continuamente um movimento de adaptação. [...] A educação seria impotente e ideológica se ignorasse o objetivo da adaptação e não preparasse os homens para se orientarem no mundo. Porém ela seria igualmente questionável se ficasse nisso, produzindo nada além de well adjusted people, pessoas bem ajustadas, em consequência do que a situação existente se impõe precisamente no que tem de pior. (ADORNO, 1995a, p. 143).

A formação é, para Adorno, subjetivação da cultura constituída tanto pela adaptação como pela emancipação. Isso confere à cultura um duplo caráter: de um lado, remete o indivíduo à sociedade e, de outro, cumpre a função de intermediação entre a sociedade e a formação do indivíduo. Em Experiências científicas nos Estados Unidos, Adorno afirma que a crítica à ideia de adaptação é lugar-comum entre os intelectuais europeus como ele, mas ressalta seu sentido propositivo ou de positividade:

Os intelectuais europeus como eu tendem a considerar o conceito de adaptação, do "adjustment", somente como algo negativo, como extinção da espontaneidade, da autonomia da pessoa individual. Mas é uma ilusão, criticada com força por Goethe e Hegel, que o processo de humanização e de formação cultural se desenvolva sempre e necessariamente de dentro 
para fora. Realiza-se, também, como dizia Hegel, precisamente mediante a alienação (Entäusserung). Não nos tornamos homens livres à medida que nos realizamos a nós mesmos como indivíduos - como reza uma formulação horrível - senão na medida em que saímos para fora de nós mesmos, vamos ao encontro dos demais e, em certo sentido, nos entregamos a eles. Somente desse modo nos definimos como indivíduos, não enquanto regamos a nós mesmos como uma plantinha com o fim de nos fazermos personalidades omnilateralmente cultas. (ADORNO, 1995b, p. 175).

Nota-se que a adaptação também faz parte do processo de formação do indivíduo, quase que como elemento necessário, de sobrevivência pessoal. A capacidade do indivíduo de se orientar no mundo e tornar-se parte dele, em grande medida, depende da adaptação. O problema ocorre quando a adaptação é tomada, e é o que acontece na sociedade "administrada", em sentido estrito e unilateral - convertida em objetivo exclusivo -, da formação do sujeito, produzindo, como o próprio Adorno afirma, nada mais do que pessoas bem ajustadas.

A emancipação é produzida, por um lado, a partir da tomada de consciência dos limites desse processo de adaptação - que facilmente leva à submissão com base no reconhecimento dos mecanismos de controle social de modo passivo -; por outro lado, pela percepção de que é preciso circunscrever as práticas de formação a partir de uma nova práxis, que considere de modo radical a capacidade que cada indivíduo tem de autorreflexão crítica, de produção de sua própria existência com autonomia e liberdade responsável. Para assumir essa direção, torna-se fundamental reconhecer a necessidade de transformar a razão instrumental em razão emancipatória. Para tanto, faz-se necessário encontrar caminhos para além da desconstrução da razão opressora pela crítica, que possam ressignificar o papel da razão e construir uma nova racionalidade fundada no princípio da "negação propositiva".

\section{Considerações finais}

Na perspectiva de Habermas, pelo medium da linguagem, a subjetividade é internamente ligada ao mundo da vida, como um horizonte aberto de possibilidades de experiências significativas e relevantes para o desenvolvimento do sujeito. O locus privilegiado da aprendizagem é a sala de aula, que deve ser um lugar denso de motivações e interações, onde se explicitam as bases conceituais 
dos saberes, processo que permite fazer o duplo sentido de traduzir o plano da realidade vivida para o plano conceitual, estabelecendo a relação entre teoria e prática e depois transpor esse plano para a realidade.

É no âmbito da própria comunicação discursiva que se cria a "esfera pública", para a ampliação gradual do diálogo e da educação que liberta e constitui a autonomia racional dos sujeitos, na medida em que o desenvolvimento da competência comunicativa, linguística, cognitiva e interativa se interconecta com o mundo da vida. Entendemos que a educação filosófica é uma ação comunicativa que envolve os seres humanos nos processos de reflexão e crítica. Sobretudo, a uma crítica material da ciência "cientificista", contra uma administração tecnocrática colonizadora do mundo da vida. Esse papel é modesto, mas indispensável para uma consciência cidadã e democrática.

Para Habermas, a educação e o ensino devem olhar para as interações e para as comunicações simbólicas como elementos centrais na possibilidade de emancipação humana, mais presentes na racionalização da cultura, ética e política do que na racionalização das forças produtivas e das relações econômicas e administrativas da colonização do mundo da vida pelos sistemas econômico e administrativo.

Da mesma forma, Adorno defende que a educação, nesse caso o ensino de Filosofia, tem de voltar-se para entender a contradição, bem como oferecer alguma forma de resistência em relação àquilo que a sociedade determina ou apresenta como dado, pronto e certo: "[...] a única concretização efetiva da emancipação consiste em que aquelas poucas pessoas interessadas nessa direção orientem toda sua energia para que a educação seja uma educação para a contradição e para a resistência" (ADORNO, 1995a, p. 183). Enfatiza, ainda, outro aspecto muito comum inerente ao ensino e às práticas escolares, que é o lugar que a competição ocupa na formação humana, sem que os educadores a percebam como uma contradição:

Partilho inteiramente do ponto de vista segundo o qual a competição é um princípio no fundo contrário a uma educação humana. De resto, acredito também que um ensino que se realiza em formas humanas de maneira alguma ultima o fortalecimento do instinto de competição. Quando muito, é possível educar dessa maneira esportistas, mas não pessoas desbarbarizadas (ADORNO, 1995a, p. 161).

Conclui-se, daí, que o modelo educacional atual e as formas de ensino necessitam de uma revisão crítica, tanto em relação aos sentidos e concepções - 
para onde se deve conduzir - como da perspectiva propositiva que indica formas de intervenção contra a (ir)racionalidade técnica que se tornou hegemônica na sociedade atual.

\section{REFERÊNCIAS}

ADORNO, T. W. Dialéctica negativa. Madrid: Taurus, 1975. $1995 \mathrm{a}$. . Educação e emancipação. Trad. Wolfgang Leo Maar. São Paulo: Paz e Terra, . Palavras e sinais. Trad. Maria Helena Ruschel. Petrópolis: Vozes, $1995 \mathrm{~b}$. ; HORKHEIMER, M. Dialética do esclarecimento. Rio de Janeiro: Zahar, 1985.

HABERMAS, Jürgen. Para reconstrução do Materialismo Histórico. São Paulo: Brasiliense, 1983.

. Mudança estrutural da esfera pública. Rio de Janeiro: Tempo Brasileiro, 1984. . Direito e moral. Lisboa: Instituto Piaget, 1986.

. Consciência moral e agir comunicativo. Rio de Janeiro: Tempo Brasileiro, 1989a.

. Teoria de la acción comunicativa: complementos y estúdios prévios. Madrid:

Cátedra, 1989b.

. Passado como futuro. Rio de Janeiro: Tempo Brasileiro, 1993.

. Direito e democracia entre facticidade e validade. Vol. I e II. Rio de Janeiro:

Tempo Brasileiro, 1997.

. Comentários à ética do discurso. Lisboa: Instituto Piaget, 1999.

. A inclusão do outro: estudos de teoria política. São Paulo: Loyola, 2002.

. Verdade e justificação: ensaios filosóficos. São Paulo: Loyola, 2004.

PUCCI, B. (Org.). Teoria crítica e educação. São Carlos: Edufscar, 1995.

REALE, G.; ANTISERI, D. História da Filosofia. São Paulo: Paulus, 1991.

REESE-SCHÄFER, Walter. Compreender Habermas. Petrópolis: Vozes, 2009.

Texto recebido em 18 de fevereiro de 2012.

Texto aprovado em 21 de junho de 2012. 